IMÁGENES EN CARDIOLOGÍA

\title{
Presentación inusual de ventana aortopulmonar e interrupción aórtica
}

\section{Unusual presentation of aortopulmonary septal defect and aortic arch interruption}

\author{
Rocío A. Peña-Juárez ${ }^{1 *}$, Miguel A. Medina-Andrade ${ }^{1}$, Carlos A. Corona-Villalobos ${ }^{2}$ y \\ Juan P. Abarca-De la Paz ${ }^{1}$
}

${ }^{1}$ Servicio de Cardiología Pediátrica, Hospital General de Occidente, Zapopan, Jalisco; ${ }^{2}$ Servicio de Cardiología Pediátrica, Instituto Nacional de Pediatría, Ciudad de México, México

La ventana aortopulmonar es una anomalía rara que representa 0.2 a $0.6 \%$ de las cardiopatías congénitas; es una comunicación entre la aorta ascendente y el tronco pulmonar (TAP) en presencia de ambos planos valvulares sigmoideos. La clasificación más empleada es la de Mori; en ésta, la de tipo II (distal), el defecto tiene forma espiral y afecta al tronco y origen de la rama derecha ${ }^{1}$. El $50 \%$ de los pacientes puede mostrar alteraciones adjuntas: la interrupción del arco aórtico representa hasta el $20 \%$, sobre todo la de tipo A (interrupción entre el origen de la arteria subclavia izquierda y la aorta descendente) $)^{2}$.

Se presenta el caso de un recién nacido con ventana aortopulmonar tipo II con origen anómalo de la rama derecha de la arteria pulmonar, la cual emerge de la porción posterior de la aorta ascendente e interrumpe el arco aórtico de tipo A. La cardiopatía se sospechó durante la exploración física por la presencia de inestabilidad hemodinámica en las primeras horas de vida y disminución de los pulsos y la presión arterial en miembros inferiores con respecto a los superiores. Las imágenes obtenidas por tomografía computarizada de multidetector de 64 cortes, realizada con protocolo

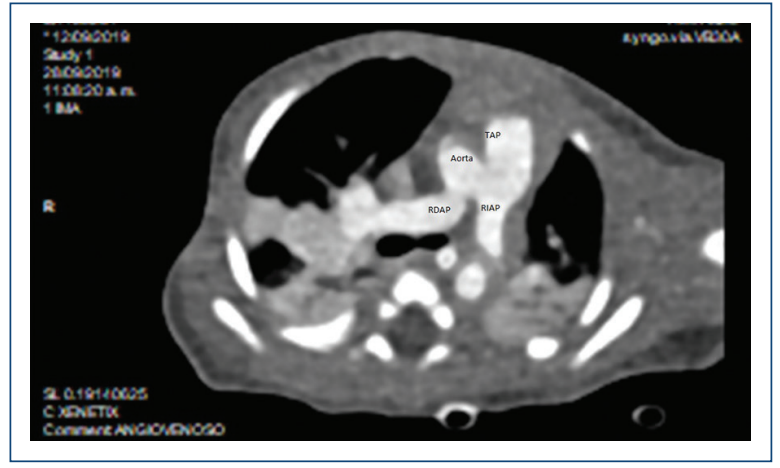

Figura 1. Ventana aortopulmonar, comunicación entre la aorta y el tronco de la arteria pulmonar (TAP); la rama derecha de la arteria pulmonar (RDAP) se origina de la aorta sin anomalías en el origen de la rama izquierda de la arteria pulmonar (RIAP).

de baja dosis ( $80 \mathrm{kV}, 50 \mathrm{~mA})$, delinearon una ventana aortopulmonar tipo 2 (Fig. 1) en la que se observaba la comunicación entre el TAP y la aorta ascendente. La rama derecha de la arteria pulmonar se originaba

\section{Correspondencia:}

*Rocío A. Peña-Juárez

E-mail: alepejz@gmail.com
Fecha de recepción: 10-01-2020

Fecha de aceptación: 11-02-2020 DOI: 10.24875/ACM.20000005
Disponible en internet: 10-03-2020 Arch Cardiol Mex. 2021;91(1):128-129

www.archivoscardiologia.com

1405-9940/@ 2020 Instituto Nacional de Cardiología Ignacio Chávez. Publicado por Permanyer. Este es un artículo open access bajo la licencia CC BY-NC-ND (http://creativecommons.org/licenses/by-nc-nd/4.0/). 


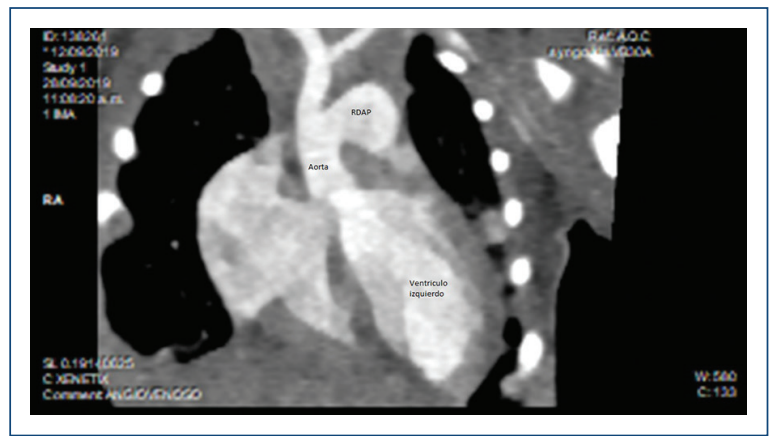

Figura 2. Se observa que la aorta emerge del ventrículo izquierdo con origen de la rama derecha de la arteria pulmonar (RDAP) de la cara posterior de la aorta ascendente.

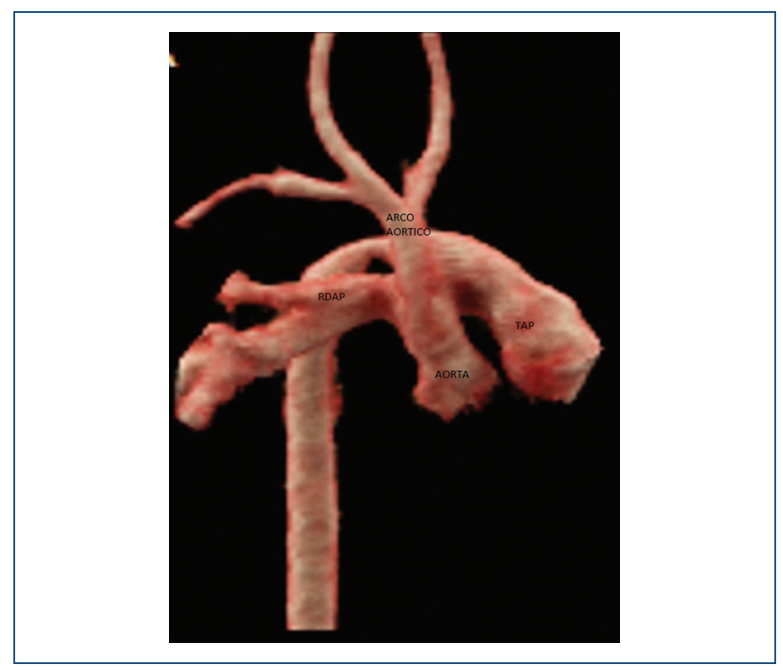

Figura 3. Origen anormal de la rama derecha de la arteria pulmonar (RDAP) e interrupción de arco aórtico tipo A. en la cara posterior de la aorta ascendente (Fig.1 y 2) y también se identificaba una interrupción del arco aórtico de tipo A (Fig. 3).

\section{Financiamiento}

Ninguno.

\section{Conflicto de intereses}

Los autores declaran no tener ningún conflicto de intereses.

\section{Responsabilidades éticas}

Protección de personas y animales. Los autores declaran que para esta investigación no se han realizado experimentos en seres humanos ni en animales.

Confidencialidad de los datos. Los autores declaran que han seguido los protocolos de su centro de trabajo sobre la publicación de datos de pacientes.

Derecho a la privacidad y consentimiento informado. Los autores han obtenido el consentimiento informado de los pacientes o sujetos referidos en el artículo. Este documento obra en poder del autor de correspondencia.

\section{Bibliografía}

1. Mori K, Ando M, Takao A, Ishikawa S, Imai Y. Distal type of aortopulmonary window. Report 4 cases. Br Heart J. 1978;40:681-9.

2. Kutsche LM, Van Mierop LHS. Anatomy and pathogenesis of aortopulmonary septal defect. Am J Cardiol. 1987:59:443-7. 